\title{
Co(II) Coordination in Prokaryotic Zinc Finger Domains as Revealed by UV-Vis Spectroscopy
}

\author{
Valeria Sivo, Gianluca D’Abrosca, Luigi Russo, Rosa Iacovino, Paolo Vincenzo Pedone, \\ Roberto Fattorusso, Carla Isernia, and Gaetano Malgieri
}

\begin{abstract}
Department of Environmental, Biological and Pharmaceutical Science and Technology, University of Campania-Luigi Vanvitelli, Via Vivaldi 43, 81100 Caserta, Italy
\end{abstract}

Correspondence should be addressed to Carla Isernia; carla.isernia@unicampania.it and Gaetano Malgieri; gaetano.malgieri@unicampania.it

Received 9 August 2017; Revised 3 October 2017; Accepted 16 October 2017; Published 14 December 2017

Academic Editor: Spyros P. Perlepes

Copyright (c) 2017 Valeria Sivo et al. This is an open access article distributed under the Creative Commons Attribution License, which permits unrestricted use, distribution, and reproduction in any medium, provided the original work is properly cited.

$\mathrm{Co}$ (II) electronic configuration allows its use as a spectroscopic probe in UV-Vis experiments to characterize the metal coordination sphere that is an essential component of the functional structure of zinc-binding proteins and to evaluate the metal ion affinities of these proteins. Here, exploiting the capability of the prokaryotic zinc finger to use different combinations of residues to properly coordinate the structural metal ion, we provide the UV-Vis characterization of Co(II) addition to Ros 87 and its mutant Ros87_C27D which bears an unusual CysAspHis 2 coordination sphere. Zinc finger sites containing only one cysteine have been infrequently characterized. We show for the CysAspHis ${ }_{2}$ coordination an intense $d$ - $d$ transition band, blue-shifted with respect to the $\mathrm{Cys}_{2} \mathrm{His}_{2}$ sphere. These data complemented by NMR and CD data demonstrate that the tetrahedral geometry of the metal site is retained also in the case of a single-cysteine coordination sphere.

\section{Introduction}

Metal ions in protein complexes exert many fundamental biological functions spanning from a simple structural role to direct participation in catalytic activities $[1,2]$. Metalloproteins are, in fact, very abundant, and many of the biological metals have $d$-orbital electrons that consent them to experience different oxidation states. Moreover, transition metals allow $d$-orbital hybridization in complex with ligands and thus coordination of more ligands and a variety of coordination geometries [3]. In the different protein sites, metal ions can be found bound to endogenous (both backbone and side chain atoms of the polypeptide) or exogenous ligands (i.e., other molecules bound to the protein) $[4,5]$. Many protein-bound metals are divalent ions, and the affinity evaluation of the protein for the metal has been the object of numerous studies [6-11]. The affinities measured in different buffers and at different $\mathrm{pH}$ values evidence their dependence upon the measurement conditions as well as the method used for the analysis. Affinity for a given metal ion, both native and exogenous, is certainly an essential information for metalloproteins' complete characterization, and whatever be the used technique, it is well known that it crucially depends on the set of coordinating amino acids.

Among the metalloproteins and metal-binding domains, the zinc finger motif, characterized by the presence of a structural zinc ion, is surely the most emblematic [12-15] as it has been intensively studied for its known ubiquitous presence in the biological world (e.g., $3 \%$ of the genes of the human genome encode for zinc fingers containing proteins $[16,17])$.

The zinc finger family is made up of several members that bind zinc with a different combination of cysteines and histidines. In the classical eukaryotic zinc fingers, also named "Kruppel ZF," two cysteines and two histidines bind zinc with high affinity. Four cysteine coordination sites and sites constituted by three Cys and one His can also be found to tightly bind the structural zinc ion, with this coordination being always essential for the domain folding [12-15].

The DNA-binding domain of the prokaryotic $\mathrm{Cys}_{2} \mathrm{His}_{2}$ zinc finger protein Ros (Ros87) folds in a domain that is structurally different and significantly larger than its eukaryotic counterpart. Ros87, held together by the structural zinc and by 
a 15-residue hydrophobic core, consists of 58 residues arranged in a $\beta \beta \beta a \alpha$ topology [18]. Numerous Ros homologues (Ros/MucR family) have been identified [14,19-24], in which the coordination sphere appears to be composed of only one (the first) cysteine [19]. The second coordinating residue is usually an aspartate, indicating for this domain the possibility of a CysAspHis ${ }_{2}$ coordination. The structural characterization of Ros87_C27D [25], an Ros87 mutant with an aspartate in the second coordinating position, has demonstrated that this residue surrogates the role of the second cysteine by monodentally coordinating the zinc ion; this mutation only slightly perturbs the functional structure of the domain.

The main issue when characterizing a zinc protein/peptide interaction is that $\mathrm{Zn}$ (II) is a $d 10$ ion, spectroscopically silent. So, if a structural change accompanies the binding, folding or unfolding [8] can be followed with circular dichroism (CD) or nuclear magnetic resonance (NMR), but in general, the most diffuse procedure to evaluate the zinc ion affinities considers a fully $\mathrm{Co}(\mathrm{II})$-loaded protein and follows the $\mathrm{Co}(\mathrm{II})$ displacement by zinc via UV-Vis spectroscopy $[6,15,26-30]$.

Cobalt(II), being a $d 7$ ion used as a probe, can substitute the native metal into both structural and catalytic metalbinding sites of the examined proteins. $\mathrm{Co}(\mathrm{II})$ and $\mathrm{Zn}$ (II) are nearly the same size [31] (ionic radius of $0.58 \AA$ and $0.60 \AA$, resp.), and many zinc-binding sites have been shown to be metal substitutable [32-35]. In some cases, enzymes with a catalytic zinc site have been shown to have similar or even higher enzymatic activity when $\mathrm{Co}(\mathrm{II})$ substitutes native $\mathrm{Zn}$ (II) [3].

Upon Co(II) coordination of ligands, a splitting of the energy levels of $d$-orbital electrons occurs. The Co(II)-ligand system absorbs light at specific wavelengths owing to the socalled $d-d$ transitions, that is, the excitation and relaxation of the $d$-orbital electrons [36]. The nature and number of coordinating ligands together with the overall coordination geometry of the system dictate the wavelengths and the intensities at which this absorption occurs $[37,38]$ : an intense band $\left(\varepsilon>300 \mathrm{M}^{-1} \mathrm{~cm}^{-1}\right)$ at $625 \pm 50 \mathrm{~nm}$ is diagnostic of a tetrahedral coordination and a weak band $\left(\varepsilon \leq 30 \mathrm{M}^{-1} \mathrm{~cm}^{-1}\right)$ at $525 \pm 50 \mathrm{~nm}$ reveals an octahedral complex. An intermediate band $\left(50 \leq \varepsilon \leq 250 \mathrm{M}^{-1} \mathrm{~cm}^{-1}\right)$ indicates a pentacoordination [26].

Co(II) gives absorption bands also at different wavelengths: due to the $\mathrm{S}^{-} \rightarrow \mathrm{Co}(\mathrm{II})$ ligand-to-metal charge transfer (LMCT), an intense absorption band in the near UV, between 316 and $340 \mathrm{~nm}$, can be observed. This band is very useful as the magnitude of the extinction coefficient at $320 \mathrm{~nm}$ permits to infer the number of $\mathrm{S}^{-}$-Co(II) bonds as each bond contributes to $\varepsilon$ by about $900-1200 \mathrm{M}^{-1} \mathrm{~cm}^{-1}$ $[39,40]$. Summarizing, while the $\varepsilon$ at $\sim 320 \mathrm{~nm}$ can count the number of $\mathrm{S}^{-}$involved in the coordination, the $\varepsilon$ at $\sim 600 \mathrm{~nm}$ is utilized to detect the coordination geometry and to hypothesize the nature of the other ligands [26].

Here, exploiting the capability of the prokaryotic zinc finger to use different combinations of residues to properly coordinate the structural metal ion $[18,25,41]$, we describe the effect of $\mathrm{Co}$ (II) binding on the larger prokaryotic zinc finger domain Ros87 and on one of its mutant Ros87_C27D.

\section{Materials and Methods}

2.1. Protein Expression and Purification. All the proteins used were expressed and purified as previously reported [42]. Only freshly prepared samples were used in all experiments. Briefly, the pet Ros56-142 (Ros87) and petRos56-142_C82D (Ros87_C27D) proteins were produced as follows: ${ }^{15} \mathrm{~N}$ labeling for NMR experiments was achieved by growing the cells at $37^{\circ} \mathrm{C}$ in a modified minimal medium containing ${ }^{15} \mathrm{NH}_{4} \mathrm{Cl}$ as the sole nitrogen source, while for UV-Vis and circular dichroism experiments, the proteins were expressed in LB medium. In both cases, the protein expression was induced for $\sim 2.0 \mathrm{~h}$ with $1.0 \mathrm{mM}$ IPTG.

The cells were then harvested, suspended in $20 \mathrm{mM}$ $\mathrm{Na}_{2} \mathrm{HPO}_{4}$ ( $\mathrm{pH}$ 6.8) buffer, and lysed by sonication. The crude cell extracts were purified by centrifugation, and the supernatant was applied to a Mono S HR 5/5 cation exchange chromatography column (Amersham Biosciences). The pooled fractions containing the proteins were applied to a HiLoad 26/60 Superdex 75 (Amersham Biosciences) gel filtration chromatography column.

2.2. UV-Vis Spectroscopy. The native zinc ion was removed obtaining apoRos87 and apoRos87_C27D by acidifying to $\mathrm{pH} 2.5$ the protein solutions in the presence of $150 \mu \mathrm{M}$ TCEP using $\mathrm{HCl} 0.1 \mathrm{M}$ and dialyzing against $10 \mathrm{mM}$ Tris, $150 \mu \mathrm{M}$ TCEP, $\mathrm{pH} 2.5$. The $\mathrm{pH}$ was finally readjusted to 6.5 , and it has been strictly controlled throughout the experiments. $\mathrm{UV}$-Vis spectra for the $\mathrm{Co}$ (II) addition experiments to Ros87 and to apoRos87_C27D were recorded in $10 \mathrm{mM}$ Tris, $20 \mu \mathrm{M}$ TCEP, pH 6.5, on a Shimadzu UV-1800 spectrophotometer in the range of $200-800 \mathrm{~nm}$ at room temperature. The apoprotein solution $(4 \mu \mathrm{M}$ in the case of Ros87 and $3 \mu \mathrm{M}$ in the case of Ros87_C27D) has been titrated with aliquots corresponding each to an increase of $0.4 \mu \mathrm{M}$ of final $\mathrm{Co}$ (II) concentration in solution for each step. $0.1 \mathrm{mM} \mathrm{CoCl}_{2}$ solution was used up to $1.6 \mathrm{Co}(\mathrm{II}) /$ protein ratio. Each experiment has been repeated at least three times obtaining comparable results. Protein concentrations were obtained using absorption at $280 \mathrm{~nm}$ at $\mathrm{pH} 2.5$.

2.3. NMR Spectroscopy. NMR samples contained $150 \mu \mathrm{M}$ of proteins in $10 \mathrm{mM}$ Tris and $150 \mu \mathrm{M}$ TCEP at $\mathrm{pH} 6.5$ in the presence of 1.4 equivalents of $\mathrm{CoCl}_{2}$ and $90 \% \mathrm{H}_{2} \mathrm{O} / 10 \%{ }^{2} \mathrm{H}_{2} \mathrm{O}$. All the HSQC spectra were recorded at $298 \mathrm{~K}$ on a Bruker Avance III HD $600 \mathrm{MHz}$ equipped with cryoprobe at the Department of Environmental, Biological and Pharmaceutical Science and Technology, University of Campania-Luigi Vanvitelli (Caserta, Italy). ${ }^{1} \mathrm{H}$ and ${ }^{15} \mathrm{~N}$ chemical shifts were calibrated indirectly by using TMS as external references. All NMR spectroscopy data were processed with the TopSpin 3.5 software (Bruker) and analyzed by using the computer-aided resonance assignment [43] (CARA) software (downloaded from cara.nmr.ch).

2.4. Circular Dichroism. Circular dichroism experiments were collected using a JASCO J-815 CD spectropolarimeter 


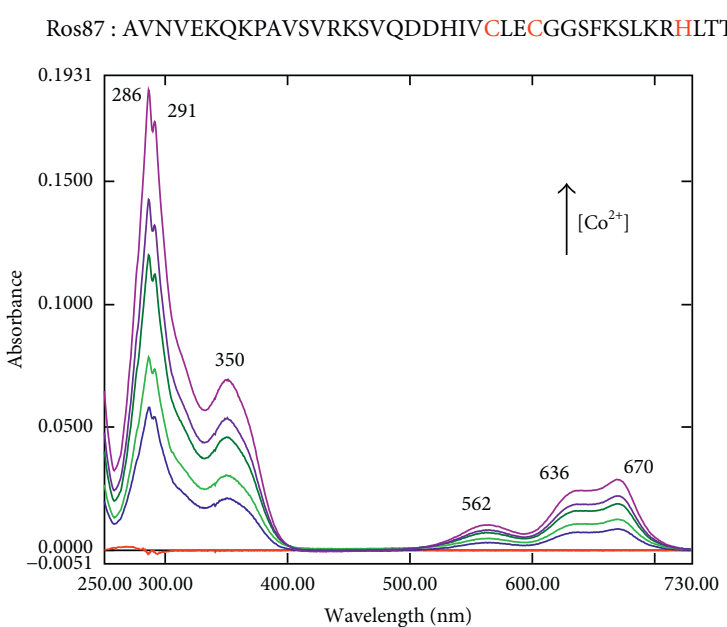

(a)

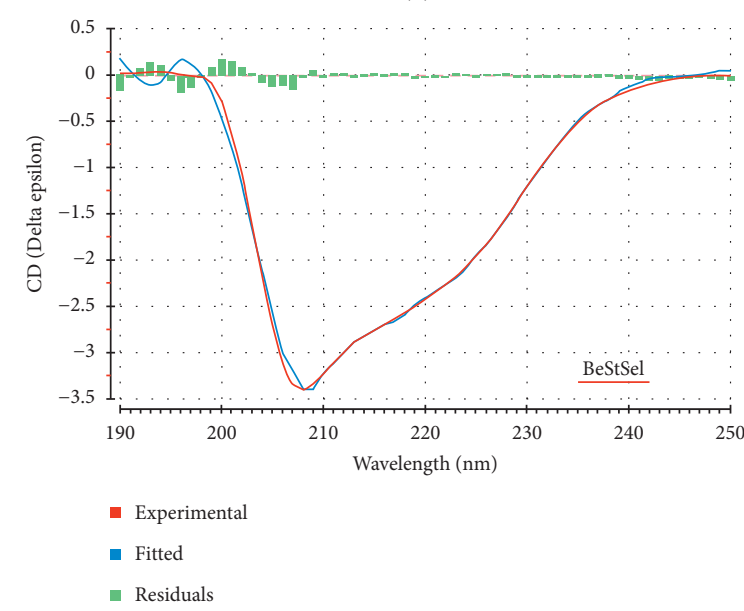

(c)

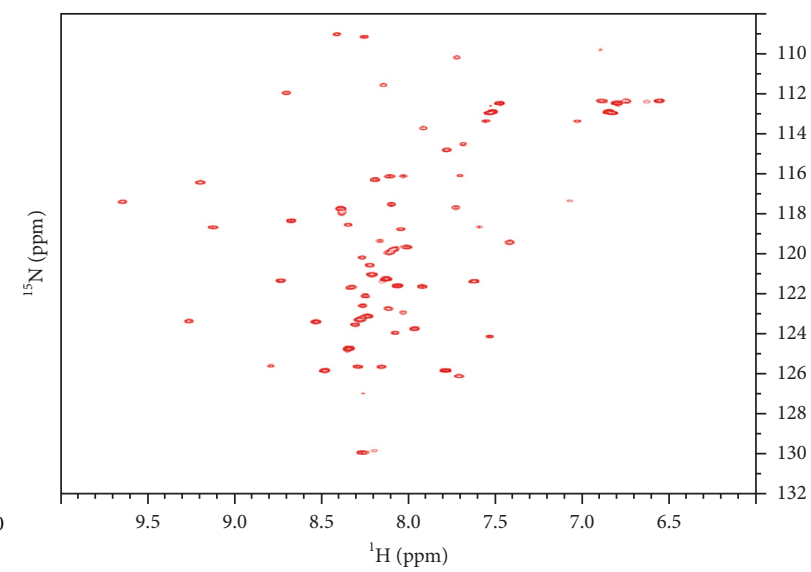

(b)

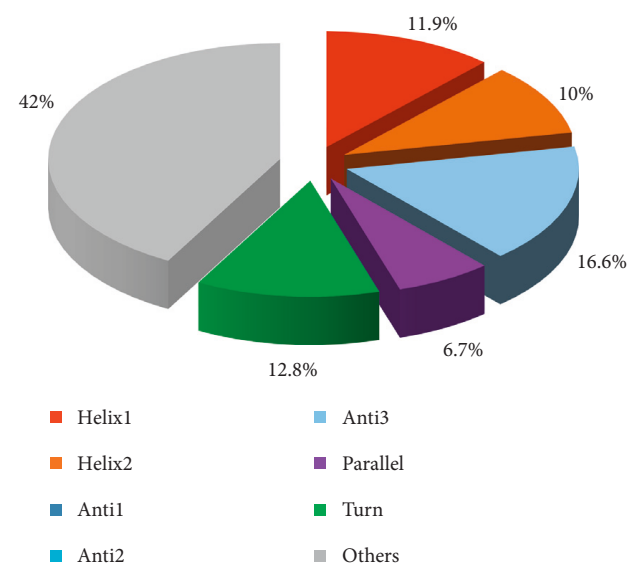

(d)

Figure 1: (Top) Ros87 amino acid sequence; (a) UV-Vis spectra of Ros87 titration with $\mathrm{CoCl}_{2}$; (b) the ${ }^{1} \mathrm{H}_{-}{ }^{15} \mathrm{~N}$ HSQC spectrum of Ros87 in the presence of 1.4 equivalents of Co(II); (c) the experimental CD spectrum of Ros87 (red) overlaid to the fitted CD data (blue) by the server BeStSel; the green histogram indicates the deviations; (d) secondary structure content calculated from the CD data by the server BeStSel.

equipped with Peltier temperature control. Data were collected in the $200-260 \mathrm{~nm}$ wavelength range using a quartz cuvette with a $1 \mathrm{~cm}$ pathlength, with a data pitch of $1 \mathrm{~nm}$, a band width of $1 \mathrm{~nm}$, and a scanning speed of $50 \mathrm{~nm} / \mathrm{min}$. All CD samples contained $\sim 15 \mu \mathrm{M}$ of proteins in $10 \mathrm{mM}$ Tris and $150 \mu \mathrm{M}$ TCEP at $\mathrm{pH}$ 6.5. A fresh solution of $\mathrm{CoCl}_{2} 5.0 \mathrm{mM}$ has been used to reach a final $\left[\mathrm{Co}^{2+}\right] /[$ protein] ratio of 1.4 . All the spectra were acquired in duplicates and were subtracted from the buffer contribution. Spectra deconvolution has been performed using the server BeStSel [44].

\section{Results and Discussion}

The UV-Vis spectra of the titration of apo-Ros87 (i.e., the unfolded prokaryotic zinc finger Ros87 with no native $\mathrm{Zn}$ (II) bound) and apo-Ros87_C27D (i.e., Ros87 with the second coordinating cysteine mutated in aspartate) with $\mathrm{CoCl}_{2}$ are shown in Figures 1(a) and 2(a).
In the case of $\mathrm{Co}$ (II)-Ros87, the $\varepsilon$ value in the near UV (at $\sim 320 \mathrm{~nm}$ ) that reflects the number of thiolate groups coordinated is $1950 \mathrm{M}^{-1} \mathrm{~cm}^{-1}$ at $350 \mathrm{~nm}$, indicating that the protein uses two thiol groups to coordinate with $\mathrm{Co}$ (II) ion. On the other hand, the $\varepsilon$ value for Co(II)-Ros87_C27D is $1020 \mathrm{M}^{-1} \mathrm{~cm}^{-1}$ at $345 \mathrm{~nm}$, indicating the involvement of one thiol group in $\mathrm{Co}$ (II) coordination. In both cases, the lack of changes in the shape of the spectrum and in the wavelength of the transition during the titration permits to exclude the formation of complexes with different protein/Co(II) ratios (i.e., $2: 1,3: 1$, or more) formed at low $\mathrm{Co}(\mathrm{II})$ concentrations [28]. This UV-Vis behaviour was previously independently seen on the same proteins in HEPES buffer [25].

Intense absorption bands around $589-670 \mathrm{~nm}$ are also observed for both proteins. These results indicate that Ros87 coordinates the $\mathrm{Co}$ (II) with a tetrahedral geometry. Also, Co (II)-Ros87_C27D exhibits an intense $d$ - $d$ absorption band centered at about $589 \mathrm{~nm}$ with the $\varepsilon$ value of $380 \mathrm{M}^{-1} \mathrm{~cm}^{-1}$ indicating also in this case a tetrahedral geometry. 
Ros87_C27D: AVNVEKQKPAVSVRKSVQDDHIVCLEDGGSFKSLKRHLTTHHSMTPEEYREKWDLPVDYPMVAPAYAEARSRLAKEMGLGQRRKANR

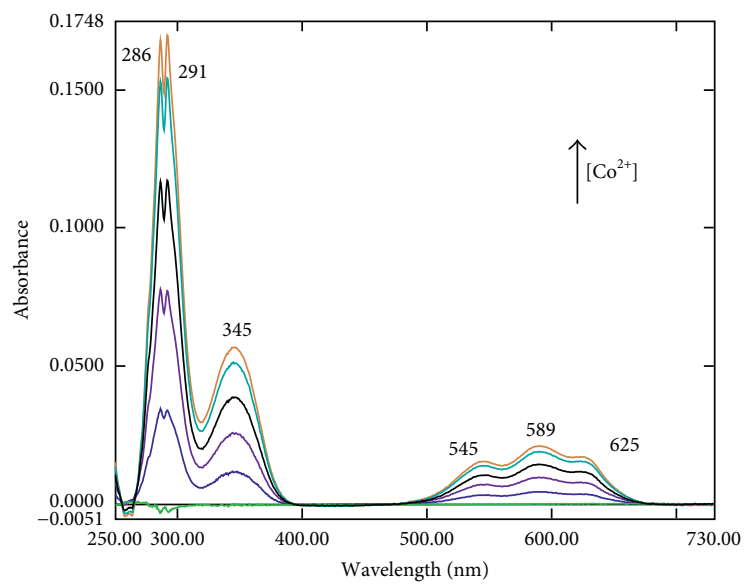

(a)

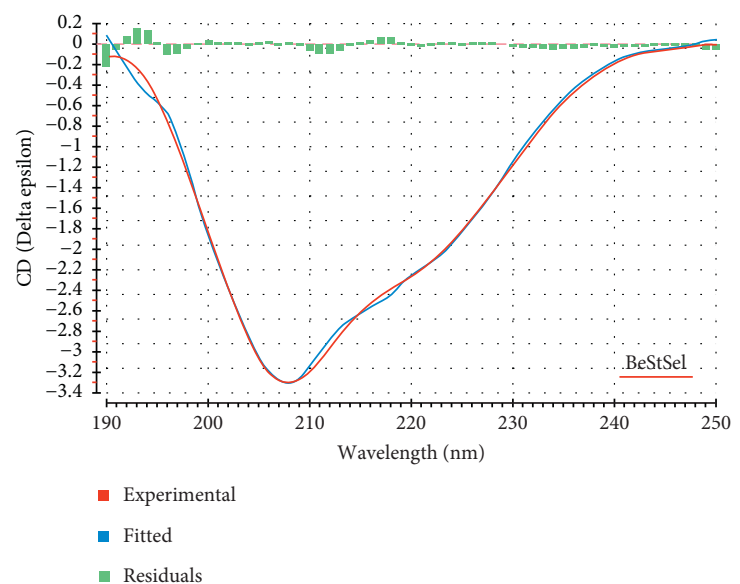

(c)

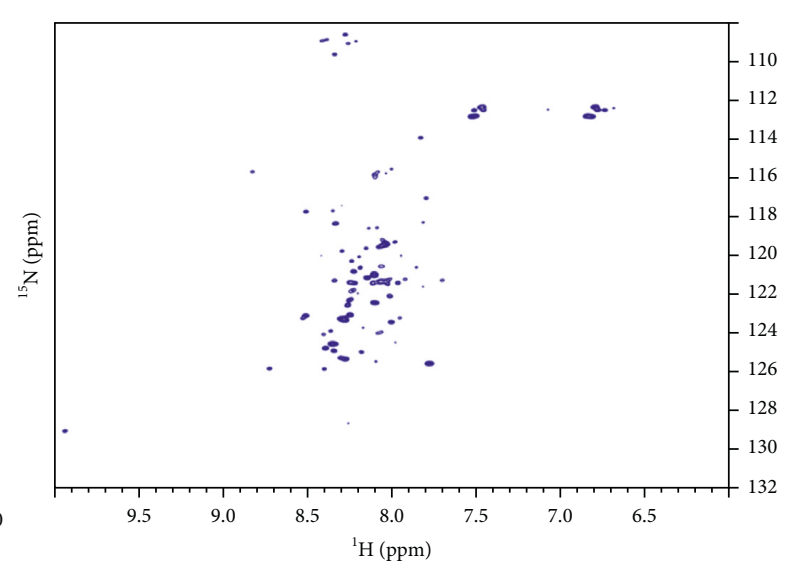

(b)

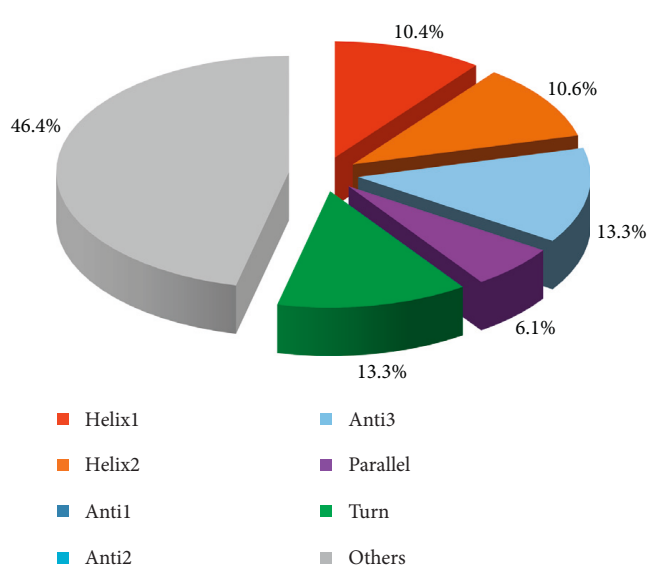

(d)

FIgure 2: (Top) Ros87_C27D amino acid sequence; (a) UV-Vis spectra of Ros87 titration with $\mathrm{CoCl}_{2}$; (b) the ${ }^{1} \mathrm{H}_{-}{ }^{15} \mathrm{~N}$ HSQC spectrum of Ros87 in the presence of 1.4 equivalents of Co(II); (c) the experimental CD spectrum of Ros87_C27D (red) overlaid to the fitted CD data (blue) by the server BeStSel; the green histogram indicates the deviations; (d) secondary structure content calculated from the CD data by the server BeStSel.

Accordingly, Figures 1(b) and 2(b) show the two ${ }^{1} \mathrm{H}_{-}{ }^{15} \mathrm{~N}$ HSQC spectra of Ros87 and Ros87_C27D, respectively, in the presence of 1.4 equivalents of Co(II) ion. Both spectra show a combination of intense and discrete signals in both proton and nitrogen dimensions indicating the interaction of Ros87 and Ros87_C27D with the paramagnetic Co(II), which gives rise in both cases to folded conformations with stable tertiary structures (Co(II)-Ros87 and $\mathrm{Co}(\mathrm{II})$-Ros87_C27D). Importantly, the two spectra show a meaningful overlap with the holo-Ros87 spectra (data not shown) in the regions not influenced by the paramagnetism of $\mathrm{Co}(\mathrm{II})$, thus suggesting for the cobalt-loaded proteins a structure very similar to the zinc-loaded proteins.

Accordingly, the CD spectra indicate that also the secondary structure content of both proteins appears to be well conserved in the $\mathrm{Co}$ (II)-loaded structures with respect to the zinc-loaded conformations (Figures 1(c) and 2(c)). In fact, both CD spectra are characteristic of well-structured proteins containing both $\alpha$-helical and $\beta$-sheet secondary structure. We estimated from the $\mathrm{CD}$ data the protein secondary structure for the two proteins using the server BeStSel (Figures 1(d) and 2(d)). This server fits the CD experimental curve by linearly combining fixed basis components to get the percentage of the eight secondary structural elements [44]. The data indicate that $\mathrm{Co}$ (II)-Ros87 and Co(II)-Ros87_C27D structures have a content of secondary structure similar to that of the Ros87calculated structure (PDB code 2JSP) and Ros87_C27D computational model [25] as determined using the software MOLMOL [45] and DSSP [46, 47].

The data reported here overall indicate for the Co(II) complexation a tetrahedral coordination geometry similar to that of the native zinc and that the replacement of the zinc ion by the $\mathrm{Co}$ (II) does not drastically perturb the structural properties of the prokaryotic zinc finger domain.

Interestingly, the comparison of the UV-Vis spectra of Ros87_C27D with those reported in literature for zinc fingers with $\mathrm{Cys}_{2} \mathrm{His}_{2}, \mathrm{Cys}_{3} \mathrm{His}$, and $\mathrm{Cys}_{4}$ coordination outlines a blue shift of the $d$ - $d$ transition bands of the protein that uses a single cysteine to coordinate the metal ion [48] (Figure 2). This shift is in agreement with what has been 


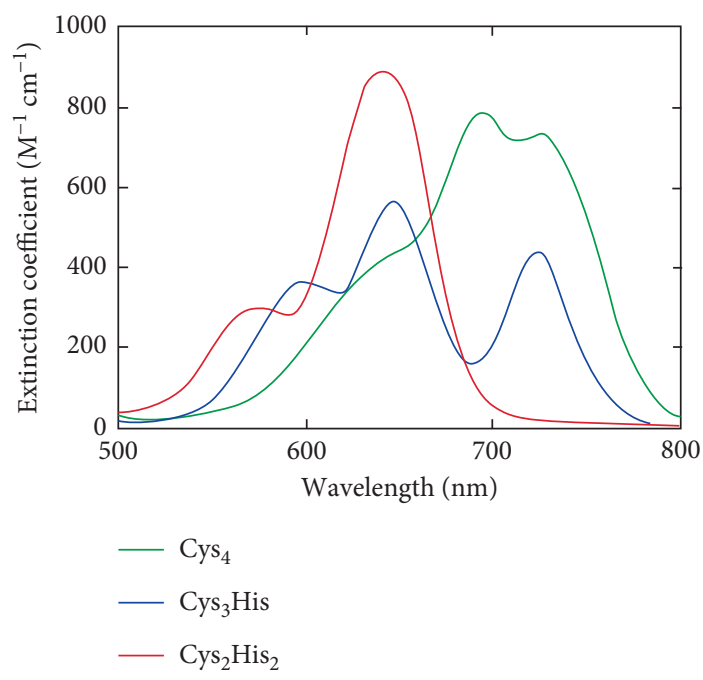

(a)

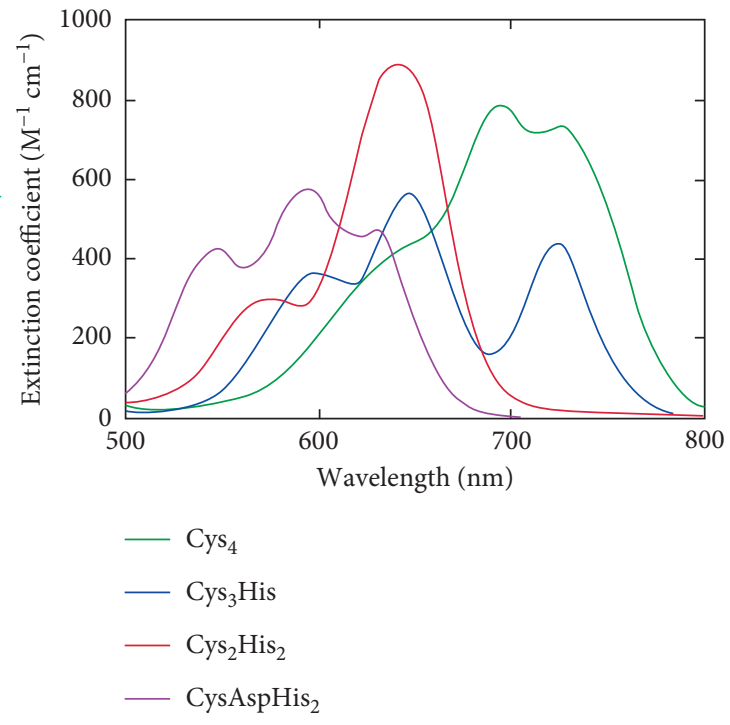

(b)

Figure 3: (a) Scheme of the UV-Vis spectra in the $500-800 \mathrm{~nm}$ range for Co(II) tetrahedral coordination by different ZFs: four Cys (green line), three Cys and one His (blue line), and two Cys and two His (red line) [37, 49]. (b) Introducing the single-cysteine coordination sphere in the scheme (violet line). The shape of the transition pattern is extremely sensitive to the structure [50].

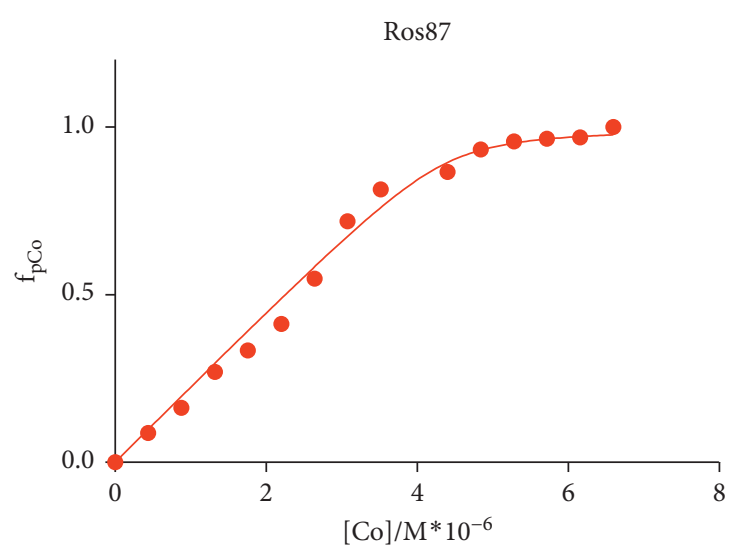

(a)

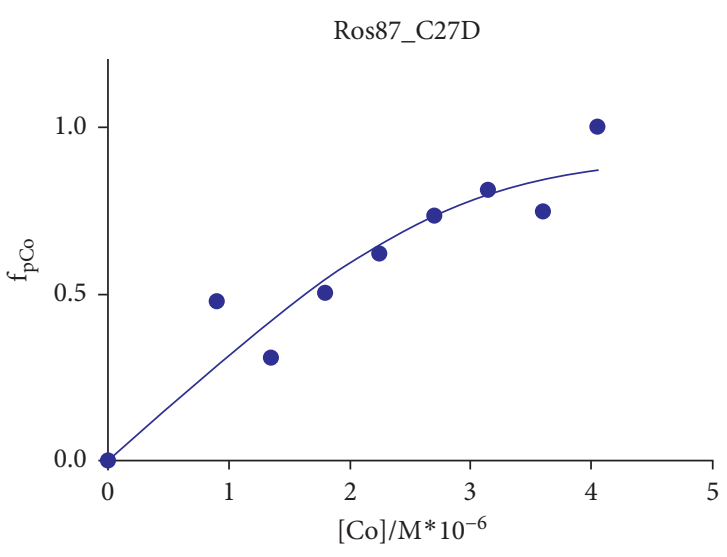

(b)

Figure 4: (a) Titration of Ros87 with $\mathrm{CoCl}_{2}$ monitored by recording the absorbance at $352 \mathrm{~nm}$. The absorbance is plotted against cobalt concentration. (b) Titration of Ros87_C27D with $\mathrm{CoCl}_{2}$ monitored by recording the absorbance at $346 \mathrm{~nm}$. The absorbance is plotted against cobalt concentration.

reported by Krizek et al. [10], who describe increasing shifts of the $d$ - $d$ transition to higher energies as the number of coordinating cysteines decreases. UV-Vis spectra of zinc finger metal sites containing only one cysteine have been rarely reported [48]. In the eukaryotic $\mathrm{Cys}_{2} \mathrm{His}_{2} \mathrm{ZF}$, the substitution of the second cysteine may result in some cases (i.e., the substitution with an aspartate or with a glutamate [48]) in coordination geometries different than the native tetrahedral coordination demonstrated by weak $d-d$ absorption bands. Here, we found an intense band at $589 \mathrm{~nm}$ that, together with NMR and CD data, indicates a tetrahedral coordination of the metal ion with a resulting blue shift of the $d$ - $d$ absorption bands. We therefore propose that the scheme of the spectra of tetrahedral coordination of $\mathrm{Co}$ (II) in zinc fingers with different numbers of cysteines and histidines (Figure 3(a)) [37, 49] can be implemented (Figure $3(\mathrm{~b})$ ) with our results.

We also determined the affinities of two proteins for $\mathrm{Co}(\mathrm{II})$, through direct titrations in Tris buffer at $\mathrm{pH} 6.5$ which shows that complexes definitively form when the $\mathrm{Co}(\mathrm{II}) /$ protein molar ratio was equal to 1.4 . Using the $1: 1$ model to fit the UV data (Figure 4) [30], we obtain a lower limit for the $\beta$ constant of $5.59( \pm 1.97) \times 10^{-8}$ for Ros87 and $2.35( \pm 0.92) \times 10^{-7}$ for Ros87_C27D.

The successive titration of the Co(II)-loaded proteins with $\mathrm{Zn}$ (II) induces a progressive reduction of both bands; the disappearance upon addition of a twofold excess of $\mathrm{Zn}$ (II) ion compared with $\mathrm{Co}$ (II) indicates that 
a Co(II) ion was substituted with the spectroscopically inert $\mathrm{Zn}(\mathrm{II})$ ion.

\section{Conclusions}

In this article, we report the spectroscopic and structural characterization of the $\mathrm{Co}(\mathrm{II})$-substituted forms of the prokaryotic zinc finger Ros87, a native zinc protein, and of its mutant Ros87_C27D in which the second coordinating cysteine is mutated to aspartate. UV-Vis spectra of zinc finger sites containing only one cysteine, neither regarding zinc, nor other metals of interest, have been rarely reported [48]. In the case of the eukaryotic $\mathrm{Cys}_{2} \mathrm{His}_{2}$ zinc finger, the substitution of the second coordinating cysteine may result in some cases (i.e., the substitution with an aspartate or with a glutamic acid [48]) in a coordination geometry different than the native tetrahedral coordination demonstrated by weak $d$ - $d$ absorption bands; when a histidine substitutes the cysteine, the coordination remains tetrahedral. Here, we show that, in the prokaryotic domain, the substitution of the native zinc with cobalt mutation does not profoundly affect the structure of the domain and that the substitution of the second ligand amino acid with an aspartate gives rise to an intense band at $589 \mathrm{~nm}$ that indicates how this substitution does not markedly change the tetrahedral coordination geometry of the metal ion. We also show how the presence of a single cysteine in the coordination sphere of the protein implies strong $d$ - $d$ absorption bands in the UV-Vis spectra, blue-shifted with respect to the two cysteines coordination.

Differently from what happens for the small eukaryotic domain, our data outline how in the case of larger proteins like Ros87_C27D, other elements composing the structure (e.g., large hydrophobic cores) play a determinant role in determining the geometry of the coordination sphere. Overall, the UV-Vis spectroscopy confirms to be an excellent and extremely sensitive tool to determine the number and geometry of ligands in structural metal sites.

\section{Conflicts of Interest}

The authors declare that there are no conflicts of interest regarding the publication of this article.

\section{Acknowledgments}

Financial support was provided by Ministero dell'Istruzione, dell'Università e della Ricerca Grant no. 20157WZM8A.

\section{References}

[1] A. L. Lehninger, D. L. Nelson, and M. M. Cox, Principles of Biochemistry: With an Extended Discussion of Oxygen-Binding Proteins, Worth Publisher, New York, NY, USA, 1993.

[2] G. Malgieri and G. Grasso, "The clearance of misfolded proteins in neurodegenerative diseases by zinc metalloproteases: an inorganic perspective," Coordination Chemistry Reviews, vol. 260, pp. 139-155, 2014.

[3] S. J. Lippard and J. M. Berg, Principles of Bioinorganic Chemistry, University Science Books, Mill Valley, CA, USA, 1994.
[4] R. H. Holm, P. Kennepohl, and E. I. Solomon, "Structural and functional aspects of metal sites in biology," Chemical Reviews, vol. 96, no. 7, pp. 2239-2314, 1996.

[5] A. Travaglia, D. La Mendola, A. Magrì et al., "Zinc(II) interactions with brain-derived neurotrophic factor $\mathrm{N}$-terminal peptide fragments: inorganic features and biological perspectives," Inorganic Chemistry, vol. 52, no. 19, pp. 1107511083, 2013.

[6] O. Sénèque and J. M. Latour, "Coordination properties of zinc finger peptides revisited: ligand competition studies reveal higher affinities for zinc and cobalt," Journal of the American Chemical Society, vol. 132, no. 50, pp. 17760-17774, 2010.

[7] T. Kochańczyk, A. Drozd, and A. Krężel, "Relationship between the architecture of zinc coordination and zinc binding affinity in proteins-insights into zinc regulation," Metallomics, vol. 7, no. 2, pp. 244-257, 2015.

[8] A. Miłoch and A. Krężel, "Metal binding properties of the zinc finger metallome-insights into variations in stability," Metallomics, vol. 6, no. 11, pp. 2015-2024, 2014.

[9] E. Kopera, T. Schwerdtle, A. Hartwig, and W. Bal, "Co(II) and $\mathrm{Cd}(\mathrm{II})$ substitute for $\mathrm{Zn}$ (II) in the zinc finger derived from the DNA repair protein XPA, demonstrating a variety of potential mechanisms of toxicity," Chemical Research in Toxicology, vol. 17, no. 11, pp. 1452-1458, 2004.

[10] B. A. Krizek, D. L. Merkle, and J. M. Berg, "Ligand variation and metal ion binding specificity in zinc finger peptides," Inorganic Chemistry, vol. 32, no. 6, pp. 937-940, 1993.

[11] J. C. Payne, B. W. Rous, A. L. Tenderholt, and H. A. Godwin, "Spectroscopic determination of the binding affinity of zinc to the DNA-binding domains of nuclear hormone receptors," Biochemistry, vol. 42, no. 48, pp. 14214-14224, 2003.

[12] J. H. Laity, B. M. Lee, and P. E. Wright, "Zinc finger proteins: new insights into structural and functional diversity," Current Opinion in Structural Biology, vol. 11, no. 1, pp. 39-46, 2001.

[13] S. S. Krishna, I. Majumdar, and N. V. Grishin, "Structural classification of zinc fingers: survey and summary," Nucleic Acids Research, vol. 31, no. 2, pp. 532-550, 2003.

[14] G. Malgieri, M. Palmieri, L. Russo, R. Fattorusso, P. V. Pedone, and C. Isernia, "The prokaryotic zinc-finger: structure, function and comparison with the eukaryotic counterpart," Federation of European Biochemical Societies Journal, vol. 282, no. 23, pp. 4480-4496, 2015.

[15] A. D. Frankel, J. M. Berg, and C. O. Pabo, "Metal-dependent folding of a single zinc finger from transcription factor IIIA," Proceedings of the National Academy of Sciences, vol. 84, no. 14, pp. 4841-4845, 1987.

[16] E. S. Lander, L. M. Linton, B. Birren et al., "Initial sequencing and analysis of the human genome," Nature, vol. 409, pp. 860-921, 2001.

[17] A. Klug, "The discovery of zinc fingers and their applications in gene regulation and genome manipulation," Annual Review of Biochemistry, vol. 79, no. 1, pp. 213-231, 2010.

[18] G. Malgieri, L. Russo, S. Esposito et al., "The prokaryotic $\mathrm{Cys}_{2} \mathrm{His}_{2}$ zinc-finger adopts a novel fold as revealed by the NMR structure of agrobacterium tumefaciens Ros DNAbinding domain," Proceedings of the National Academy of Sciences, vol. 104, no. 44, pp. 17341-17346, 2007.

[19] I. Baglivo, L. Russo, S. Esposito et al., "The structural role of the zinc ion can be dispensable in prokaryotic zinc-finger domains," Proceedings of the National Academy of Sciences, vol. 106, no. 17, pp. 6933-6938, 2009.

[20] C. Fumeaux, S. K. Radhakrishnan, S. Ardissone et al., "Cell cycle transition from S-phase to G1 in caulobacter is mediated 
by ancestral virulence regulators," Nature Communications, vol. 5, p. 4081, 2014.

[21] G. Panis, S. R. Murray, and P. H. Viollier, "Versatility of global transcriptional regulators in alpha-Proteobacteria: from essential cell cycle control to ancillary functions," Federation of European Microbiological Societies Microbiology Reviews, vol. 39, no. 1, pp. 120-133, 2015.

[22] D. Moreira and F. Rodríguez-Valera, "A mitochondrial origin for eukaryotic $\mathrm{C} 2 \mathrm{H} 2$ zinc finger regulators?" Trends in $\mathrm{Mi}$ crobiology, vol. 8, no. 10, pp. 448-450, 2000.

[23] E. Moreno, E. Stackebrandt, M. Dorsch, J. Wolters, M. Busch, and H. Mayer, "Brucella abortus 16S rRNA and lipid a reveal a phylogenetic relationship with members of the alpha-2 subdivision of the class proteobacteria," Journal of Bacteriology, vol. 172, no. 7, pp. 3569-3576, 1990.

[24] I. Baglivo, M. Palmieri, A. Rivellino et al., "Molecular strategies to replace the structural metal site in the prokaryotic zinc finger domain," Biochimica et Biophysica Acta (BBA)-Proteins and Proteomics, vol. 1844, no. 3, pp. 497-504, 2014.

[25] G. D'Abrosca, L. Russo, M. Palmieri et al., "The (unusual) aspartic acid in the metal coordination sphere of the prokaryotic zinc finger domain," Journal of Inorganic Biochemistry, vol. 161, pp. 91-98, 2016.

[26] A. Nomura and Y. Sugiura, "Contribution of individual zinc ligands to metal binding and peptide folding of zinc finger peptides," Inorganic Chemistry, vol. 41, no. 14, pp. 3693-3698, 2002.

[27] W. Kou, H. S. Kolla, A. Ortiz-Acevedo, D. C. Haines, M. Junker, and G. R. Dieckmann, "Modulation of zinc- and cobalt-binding affinities through changes in the stability of the zinc ribbon protein 136," Journal of Biological Inorganic Chemistry, vol. 10, no. 2, pp. 167-180, 2005.

[28] S. F. Michael, V. J. Kilfoil, M. H. Schmidt, B. T. Amann, and J. M. Berg, "Metal binding and folding properties of a minimalist $\mathrm{Cys}_{2} \mathrm{His}_{2}$ zinc finger peptide," Proceedings of the National Academy of Sciences, vol. 89, no. 11, pp. 4796-4800, 1992.

[29] M. C. Posewitz and D. E. Wilcox, "Properties of the Sp1 zinc finger 3 peptide: coordination chemistry, redox reactions, and metal binding competition with metallothionein," Chemical Research in Toxicology, vol. 8, no. 8, pp. 1020-1028, 1995.

[30] C. Isernia, E. Bucci, M. Leone et al., "NMR structure of the single qalggh zinc finger domain from the arabidopsis thaliana superman protein," Chembiochem, vol. 4, no. 2-3, pp. 171-180, 2003.

[31] I. Bertini, H. B. Gray, E. I. Stiefel, and J. S. Valentine, Biological Inorganic Chemistry: Structure and Reactivity, University Science Books, Sausalito, CA, USA, 2007.

[32] G. Malgieri, L. Zaccaro, M. Leone et al., "Zinc to cadmium replacement in the A. thaliana SUPERMAN $\mathrm{Cys}_{2} \mathrm{His}_{2}$ zinc finger induces structural rearrangements of typical DNA base determinant positions," Biopolymers, vol. 95, no. 11, pp. 801-810, 2011.

[33] G. Malgieri, M. Palmieri, S. Esposito et al., "Zinc to cadmium replacement in the prokaryotic zinc-finger domain," Metallomics, vol. 6, no. 1, pp. 96-104, 2014.

[34] R. Gessmann, C. Kyvelidou, M. Papadovasilaki, and K. Petratos, "The crystal structure of cobalt-substituted pseudoazurin from Alcaligenes faecalis," Biopolymers, vol. 95, no. 3, pp. 202-207, 2011.

[35] C. J. Walsby, D. Krepkiy, D. H. Petering, and B. M. Hoffman, "Cobalt-substituted zinc finger 3 of transcription factor IIIA: interactions with cognate DNA detected by (31)P ENDOR spectroscopy," Journal of the American Chemical Society, vol. 125 , no. 25 , pp. $7502-7503,2003$

[36] M. T. Worthington, B. T. Amann, D. Nathans, and J. M. Berg, "Metal binding properties and secondary structure of the zinc-binding domain of Nup475," Proceedings of the National Academy of Sciences, vol. 93, no. 24, pp. 13754-13759, 1996.

[37] Y. Shi, R. D. Beger, and J. M. Berg, "Metal binding properties of single amino acid deletion mutants of zinc finger peptides: studies using cobalt(II) as a spectroscopic probe," Biophysical Journal, vol. 64, no. 3, pp. 749-753, 1993.

[38] I. Bertini and C. Luchinat, "High spin cobalt(II) as a probe for the investigation of metalloproteins," Advances in Inorganic Biochemistry, vol. 6, pp. 71-111, 1984.

[39] S. W. May and J-Y. Kuo, "Preparation and properties of cobalt (II) rubredoxin,” Biochemistry, vol. 17, no. 16, pp. 3333-3338, 1978.

[40] M. Vasák, J. H. Kägi, B. Holmquist, and B. L. Vallee, "Spectral studies of cobalt(II)- and nickel(II)-metallothionein," Biochemistry, vol. 20, no. 23, pp. 6659-6664, 1981.

[41] M. Palmieri, L. Russo, G. Malgieri et al., "Deciphering the zinc coordination properties of the prokaryotic zinc finger domain: the solution structure characterization of Ros 87 H42A functional mutant," Journal of Inorganic Biochemistry, vol. 131, pp. 30-36, 2014.

[42] S. Esposito, I. Baglivo, G. Malgieri et al., "A novel type of zinc finger DNA binding domain in the agrobacterium tumefaciens transcriptional regulator Ros," Biochemistry, vol. 45, no. 34, pp. 10394-10405, 2006.

[43] C. Bartels, T. H. Xia, M. Billeter, P. Güntert, and K. Wüthrich, "The program XEASY for computer-supported NMR spectral analysis of biological macromolecules," Journal of Biomolecular NMR, vol. 6, no. 1, pp. 1-10, 1995.

[44] A. Micsonai, F. Wien, L. Kernya et al., "Accurate secondary structure prediction and fold recognition for circular dichroism spectroscopy," Proceedings of the National Academy of Sciences, vol. 112, no. 24, pp. E3095-E3103, 2015.

[45] R. Koradi, M. Billeter, and K. Wüthrich, "MOLMOL: a program for display and analysis of macromolecular structures," Journal of Molecular Graphics, vol. 14, pp. 51-55, 1996.

[46] W. G. Touw, C. Baakman, J. Black et al., "A series of PDBrelated databanks for everyday needs," Nucleic Acids Research, vol. 43, pp. D364-D368, 2015.

[47] W. Kabsch and C. Sander, "Dictionary of protein secondary structure: pattern recognition of hydrogen-bonded and geometrical features," Biopolymers, vol. 22, no. 12, pp. $2577-$ 2637, 1983.

[48] M. Imanishi, K. Matsumura, S. Tsuji et al., "Zn(II) binding and DNA binding properties of ligand-substituted CXHHtype zinc finger proteins," Biochemistry, vol. 51, no. 16, pp. 3342-3348, 2012.

[49] J. L. Michalek, A. N. Besold, and S. L. Michel, "Cysteine and histidine shuffling: mixing and matching cysteine and histidine residues in zinc finger proteins to afford different folds and function," Dalton Transactions, vol. 40, no. 47, pp. 12619-12632, 2011.

[50] O. Sénèque, E. Bonnet, F. L. Joumas, and J. M. Latour, "Cooperative metal binding and helical folding in model peptides of treble-clef zinc fingers," Chemistry-A European Journal, vol. 15, no. 19, pp. 4798-4810, 2009. 

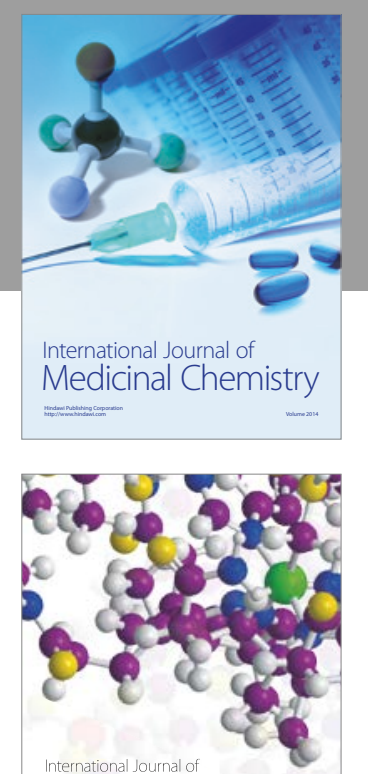

Carbohydrate Chemistry

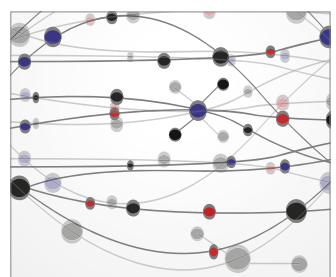

The Scientific World Journal
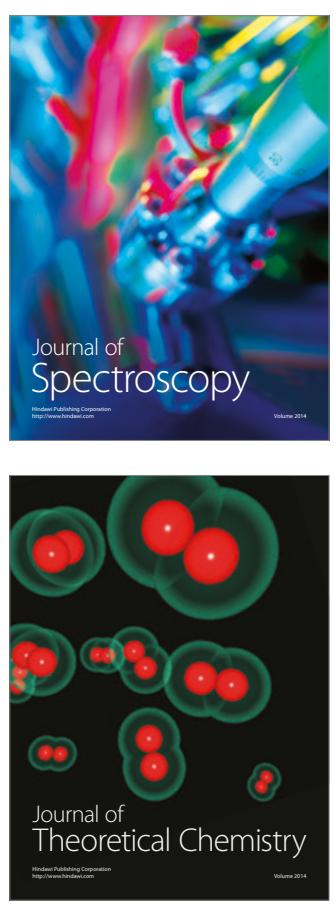
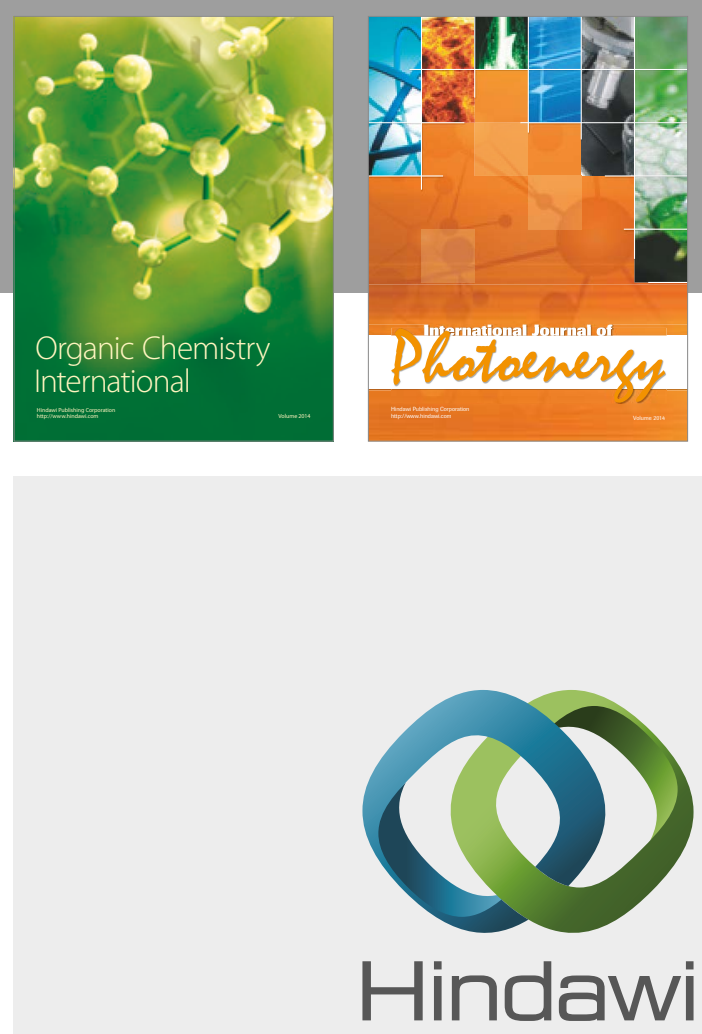

Submit your manuscripts at

https://www.hindawi.com

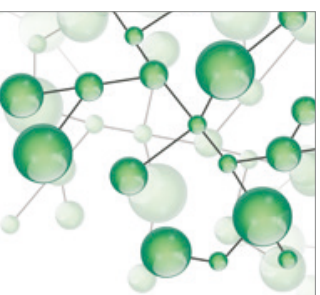

International Journal of

Inorganic Chemistry

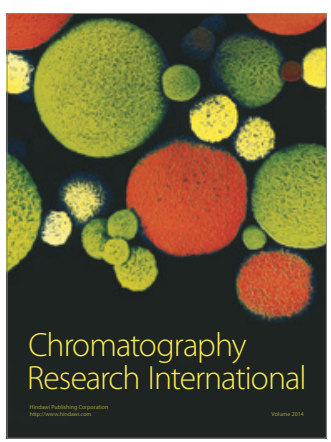

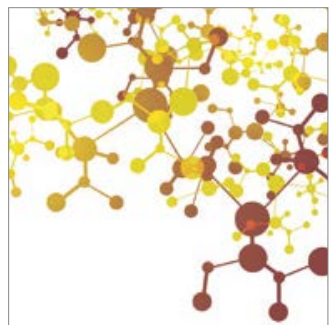

Applied Chemistry
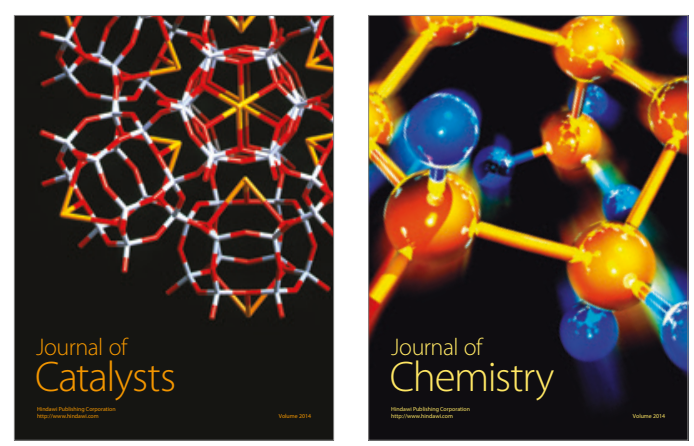
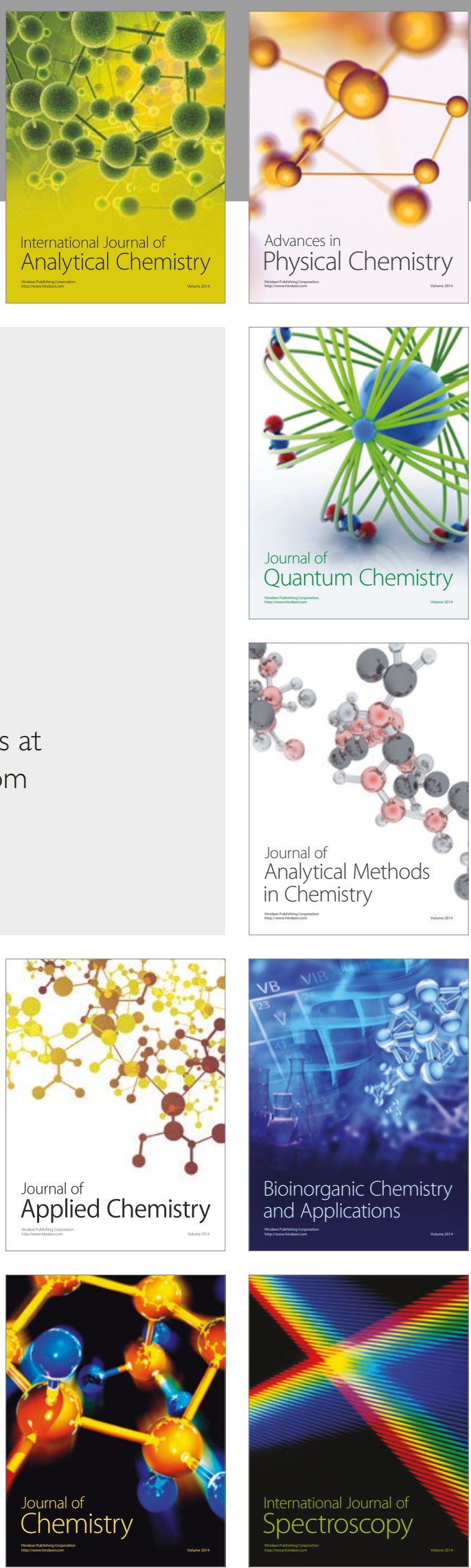